EVALUASI, 3(2), September 2019, ISSN 2580-3387 (print) |

ISSN 2615-2886 (online)

Homepage : http://e-journal.staima-alhikam.ac.id/index.php/evaluasi

DOI : : http://doi.org/10.32478/evaluasi.v3i2.262

Article type : Original Research Article

\title{
Penerapan Metode Tsaqifa Dengan Metode Kooperatif Pada Pengajaran \\ Baca Al-Quran Kelompok Pengajian Muslimah Dusun Pokoh Desa Wonoboyo Kecamatan Wonogiri Kabupaten Wonogiri
}

Oleh: Dhini Rahmawati

Program Pascasarjana IAIN SURAKARTA

\begin{abstract}
The general objective of this research was to study the method of applying Tsaqifa in; recitation of Muslim recitation of Pokoh hamlet Wonoboyo village Wonogiri sub-district Wonogiri. The specific objectives of this study were; (1) Learning the plan of applying the Tsaqifa method with cooperative learning method (2) Learning the application of the Tsaqifa method with cooperative learning method (3) Learning the result of applying the Tsaqifa method with cooperative learning method. The research method was used qualitative field study (field research). Data collection technique through observations, interviews, documentations and triangulations. Data analysis techniques were using data reduction, data presentation and drawing conclusion. The results of this study concluded that; (1) With the application of Tsaqifa and this cooperative method, it is able to complete the Muslimah recitation group members of Pokoh hamlet in Wonoboyo village, Wonogiri sub-district from illiteracy of Hijaiyyah. (2) The application of the Tsaqifa method in the study group follows practical tahsin learning by taking turns recitations after the program finishes. (3) To support the smooth reading of the Qur'an, it was followed up with rotating recitation every week.
\end{abstract}

Keywords: Thaqifa Method, Hijaiyyah Script Blindness, Learning to Read Hijaiyyah Letters, Reading Al-Qur'an

Email address: Dick.dhini@gmail.com

EVALUASI: Jurnal Manajemen Pendidikan is licensed under The CC BY License (https://creativecommons.org/licenses/by-sa/4.0/) 
EVALUASI, 3(2), September 2019, ISSN 2580-3387 (print) |

ISSN 2615-2886 (online)

http://doi.org/10.32478/evaluasi.v3i2.262

\begin{abstract}
Abstrak
Tujuan umum penelitian ini adalah untuk mengetahui penerapan metode Tsaqifa di;ingkup pengajian muslimah dusun Pokoh desa Wonoboyo kecamatan Wonogiri kabupaten Wonogiri. Tujuan khusus penelitian ini adalah; (1) mengetahui perencanaan penerapan metode Tsaqifa dengan metode pembelajaran kooperatif (2) mengetahui penerapan metode Tsaqifa dengan metode pembelajaran kooperatif (3) mengetahui hasil penerapan metode Tsaqifa dengan metode pembelajaran kooperatif. Metode penelitian yang digunakan adalah penelitian kualitatif study lapangan (penelitian lapangan). Teknik pengumpulan data melalui observasi, wawancara, dokumentasi dan triangulasi. Teknik analisis data menggunakan reduksi data, penyajian data dan penarikan kesimpulan. Hasil penelitian ini menyimpulkan bahwa; (1) Dengan penerapan Tsaqifa dan metode kooperatif ini mampu menuntaskan anggota kelompok pengajian muslimah dusun Pokoh desa Wonoboyo kecamatan Wonogiri dari buta aksara Hijaiyyah. (2) Penerapan metode Tsaqifa dalam kelompok pengajian ini diikuti dengan pembelajaran tahsin praktis dengan cara tilawah bergilir setelah selesai program. (3) Untuk menunjang kelancaran membaca Al-Quran, ditindak lanjuti dengan tilawah bergilir setiap pekannya.
\end{abstract}

Kata kunci: Metode Tsaqifa, Bebas Buta Aksara Hijaiyyah, Belajar Membaca Huruf Hijaiyyah, Baca Tulis Al-Quran.

\title{
A. Pendahuluan
}

Cepat lambatnya seseorang dalam menguasai bacaan Al-Quran adalah kemauannya untuk belajar. Selain kemauan, metode belajar baca Al-Quranpun juga menjadi sarana penting sebagai penentu cepat lambatnya seseorang menguasai bacaan Al-Qurannya.

Salah satu metode baca Al-Quran yang sedang digunakan adalah metode Tsaqifa. Dalam sebuah pengajian muslimah dusun Pokoh desa Wonogiri sudah menguanakan metode ini untuk belajar baca Al-Quran.

Salah satu hal yang melatarbelakangi pemilihan judul ini adalah keinginan penulis untuk mengetahui bagaimana penerapan metode 
tsaqifa dengan metode kooperatif dalam pengajaran baca Al-Quran kelompok pengajian muslimah dusun Pokoh desa Wonoboyo kecamatan Wonogiri.

Dalam hal ini penulis ingin mengetahui bagaimana perencanaan penerapan metode Tsaqifa dengan kooperatif ini untuk para ibu rumah tangga dalam kelompok pengajian tersebut.

Selain itu, penulis ingin mengetahui penerapan metode ini secara langsung di lingkungan masyarakat, terutama waktu dilaksanakannya pengajaran baca Al-Quran serta waktu yang dibutuhkan hingga menguasai huruf hijjaiyyah dalam baca Al-Quran. Bahkan waktu yang diperlukan hingga bisa lancar membaca Al-Quran.

Untuk pemilihan tempat dan lokasi penulis memilih di dusun Pokoh desa Wonoboyo kecamatan Wonogiri. Dengan alasan bahwa di tempat tersebut sudah mengguanakan metode Tsaqifa ini secara berkelanjutan dengan bantuan seorang pengajar Al-Quran.

Dari hal-hal yang melatarbelakangi masalah ini maka penelitian dengan judul "Penerapan Metode Tsaqifa Dengan Metode Kooperatif Pada Pengajaran Baca Al-Quran Kelompok Pengajian Muslimah Dusun Pokoh Desa Wonoboyo Kecamatan Wonogiri Kabupaten Wonogiri" layak dilakukan.

\section{B. Kajian Teori}

\section{Metode Tsaqifa}

a. Pengertian Metode Tsaqifa

Tsaqifa artinya cerdik atau cerdas adalah sebuah metode pembelajaran baca Al-Quran yang dirancang untuk kalangan pelajar dan orang dewasa bukan untuk anak-anak. Metode ini menggunakan konsep kemandirian dan sistem 5 kali pertemuan bisa membaca Al-Quran.

Tsaqifa adalah metode belajar baca Al-Quran mudah dan praktis yang siapa saja dapat mempelajarinya, baik pernah 
EVALUASI, 3(2), September 2019, ISSN 2580-3387 (print) |

ISSN 2615-2886 (online)

http://doi.org/10.32478/evaluasi.v3i2.262

mengaji atau belum pernah sama sekali. Metode ini mempunyai beberapa karakteristik, diantaranya adalah: ${ }^{1}$

1) Sistematis, artinya pola yang dipergunakan dalam setiap pembahasan adalah pola tetap, berurutan dab berkesinambungan.

2) Fleksibel, metode ini dapat diajarkan dengan sistem fardiyah (privat) ataupun jama'aiyah (klasikal) serta bisa diajarkan kepada semua kalangan orang tua maupun anak-anak usia 10 tahun keatas.

3) Praktis, untuk dapat membaca Al-Quran dibutuhkan waktu singkat hanya dengan 5 kali pertemuan dengan masingmasing pertemuan 1,5 jam.

4) Variatif, setiap pembahasan mempunyai cara pengajaran yang berbeda.

5) CBSA, Cara Belajar Siswa Aktif.

b. Tahapan-Tahapan Pengajaran Tsaqifa

Dalam pengajaran Tsaqifa ini terdapat 3 tahapan penting yang harus dilalui, ${ }^{2}$ tahapan- tahapan tersebut adalah:

1) Tahapan pertama, menguasai huruf hijaiyyah dan perubahannya dengan alokasi waktu kurang lebih 3jam, pembagiannya sebagai berikut:

a) $1 \frac{1}{2}$ jam pengenalan 18 huruf hijaiyyah dan perubahannya. Yaitu pengenalan huruf-huruf yang berkonsonan sama dengan huruf latin, terdapat 18 huruf. 18 huruf ini disusun sebagai berikut Na-Ma (ن) Sa-Ya (س-م) Ma-La (J-م) Ro-Sa (ك-ر) / Ka-Ta (ك-ت) Wa-

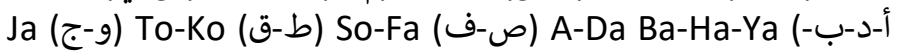
(ه).

b) 2) 1 jam pengenalan 10 huruf hijayyah dan perubahannya. Yaitu pengenalan huruf yang

${ }^{1}$ Umar Taqwim. Tsaqifa, Cara Cepat dan Mudah Belajar Membaca AlQuran.Cetakan ke-30. Magelang: Adz-Dzikr. Hal. 8

2 Umar Taqwim. 7 1/2 Jam Bisa Membaca Al-Quran.Cetakan ke-VII .Sukoharjo: Nur Cahaya Ilmu. Hal: 12 
EVALUASI, 3(2), September 2019, ISSN 2580-3387 (print) |

ISSN 2615-2886 (online)

http://doi.org/10.32478/evaluasi.v3i2.262

konsonannya tidak sama dengan huruf latin, terdapat 10

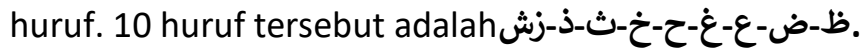

2) Tahapan kedua, menguasai tanda baca. Dalam tahapan ini dibagi dalam beberapa bab yang harus dipelajari, setidaknya mendapatkan alokasi kurang lebih 3jam, dengan pembagian sebagai berikut:

a) 15 mneit mengenal Vokal a-i-u dan perubahannya.

b) 45 menit mengenal bunyi akhiran $-\mathrm{n}$ atau tanwin.

c) 45 menit mengenal vokal panjang (aa-ii-uu) atau bacaan panjang.

d) 45 menit mengenal huruf mati atau sukun.

e) 45 menit mengenal huruf doble atau tasydid.

3) Tahapan ketiga, mempraktekkan semaksimal mungkin. Alokasi waktu dalam tahap ini adalah $1 \frac{1}{2} \mathrm{jam}$. Dibagian ini terbagi menjadi 3 tahapan, yaitu:

a) 15 menit latihan membaca potongan ayat-ayat AlQuran.

b) Selanjutnya latihan membaca Al-Quran. Dalam latihan membaca Al-Quran ini setiap peserta diberikan kesempatan untuk meluangkan waktu setiap harinya untuk membaca Al-Quran 15-20 menit saja agar bacaan lancar.

c) Bagian terakhir adalah pengenalan tajwid terapan secara global.

\section{Metode Kooperatif}

a. Pengertian Metode Kooperatif

Pengertian pembelajaran kooperatif merupakan pembelajaran dengan cara belajar dan bekerja dalam kelompokkelompok kecil secara kolaboratif yang anggotanya terdiri dari empat sampai enam anggota dengan struktur anggota yang 
EVALUASI, 3(2), September 2019, ISSN 2580-3387 (print) |

ISSN 2615-2886 (online)

http://doi.org/10.32478/evaluasi.v3i2.262

bersifat heterogen. ${ }^{3}$ Sedangkan langkah-langkah atau prosedur pembelajaran kooperatif adalah sebagai berikut: ${ }^{4}$

1) Tahap 1 penyampaian tujuan yang ingin dicapai pada pelajaran tersebut dan memotivasi siswa untuk belajar.

2) Tahap 2 penyajian informasi atau materi oleh guru kepada siswa.

3) Tahap 3 pengorganisasian siswa kedalam kelompokkelompok belajar dengan bimbingan dari guru agar melakukan transisi secara efektif dan efisien.

4) Tahap 4 pembimbingan kelompok bekerja dan belajar dalam mengerjakan tugas kelompok.

5) Tahap 5 evaluasi hasil belajar, bisa dalam bentuk presentasi kelompok.

6) Tahap 6 pemberian penghargaan.

b. Macam-Macam Metode Kooperatif

Metode pembelajaran kooperatif ini memiliki beberapa variasi pendekatan, kami akan memaparkan 4 variasi pendekatan dalam pembelajaran kooperatif, diantaranya adalah:

1) STAD (Student Teams Achievement Division)

Pembelajaran kooperatif model ini beranggotakan empat sampai lima orang yang beragam kemudian guru memberikan suatu pelajaran pada kelompok tersebut dan memberikan kuis kepada masing-masing anggota kelompok untuk mengetahui penguasaan materi yang disampaikan. Dalam pembelajaran kooperatif tipe STAD ini terdapat beberapa langkah yaitu menyampaikan tujuan dan memotivasi siswa, menyajikan informasi, mengorganisasikan siswa dalam kelompok-kelompok belajar, evaluasi dan memberikan penghargaan. ${ }^{5}$

2) JIGSAW (Tim Ahli)

${ }^{3}$ Rusman. Model-Model Pembelajaran Mengembangkan Profesionalisme Guru. Cetakan ke-5. Depok:Raja Grafindo Persada. 2012 Hal. 202

${ }^{4}$ Trianto. Mendesain Model Pembelajaran Inovatif-Progresif. Cetakan ke-1. Jakarta: Kencana. 2009. Hal.66-67.

${ }^{5}$ Trianto. Op Cit. Hal.21 
Model ini membagi sebuah topik yang menjadi komponen-komponen subtopik kemudian guru membagi siswa kedalam kelompok yang terdiri dari empat sampai lima orang dengan pembagian tugas atau subtopik yang berbeda. Masing-masing anggota kelompok yang memiliki tugas di subtopik yang sama membuat kelompok baru untuk belajar dan menjadi ahli dalam subtopik yang menjadi tugasnya.

Langkah-langkah dalam pembelajaran jigsaw ini secara terperinci adalah pembagian kelompok dengan anggota 4-5 orang, pemberian materi, pembentukan tim ahli, tiap anggota tim ahli kembali kedalam kelompok semula, tim ahli mempresentasikan hasil diskusi, pembahasan dan penutup $^{6}$

3) Investigasi Kelompok

Kelompok dalam model ini dibentuk oleh siswa dengan beranggotakan 2-6 orang, bebas memilih subtopik dari materi yang diajarkankemudian membuat laporan untuk dipresentasikan didepan kelompok lain.

Langkah-langkah dalam model ini antara lain adalah membagi kelompok yang terdiri kurang lebih 5 orang, memberikan pertanyaan yang bersifat analitis dan mengajak setiap siswa berpartisipasi dalam menjawab pertanyaan dalam kelompoknya secara bergiliran. ${ }^{7}$

4) Struktural

Dalam model ini, kelompok siswa bervariasi mulai dari berdua, bertiga, ataupun dalam kelompok dengan jumlah 4-6 anggota. Tujuan dalam kelompok ini adalah ketrampilan kelompok dan ketrampilan sosial. Tugas utama kelompok ini adalah mengerjakan tugas-tugas yang diberikan secara kognitif ataupun sosial. Penekanan dalam kelompok ini adalah interaksi siswa dengan siswa dan hubungan antara yang dilakukan siswa dengan yang dipelajari siswa karena hal

\footnotetext{
${ }^{6}$ Rusman, Op Cit, Hal 218

${ }^{7}$ Rusman, Op Cit, Hal 223
} 
EVALUASI, 3(2), September 2019, ISSN 2580-3387 (print) |

ISSN 2615-2886 (online)

http://doi.org/10.32478/evaluasi.v3i2.262

ini berpengaruh terhadap sisi sosial, kognitif dan akademisnya. ${ }^{8}$

\section{Baca Al-Quran}

a. Pengertian Baca Al-Quran

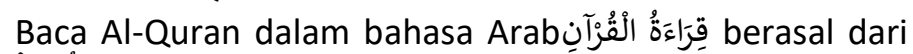

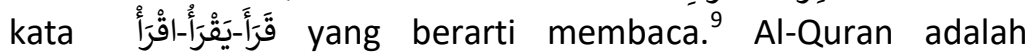
kitabullah yang diturunkan kepada Nabi Muhammad SAW yang terjaga dari pengurangan dan penambahan isi ataupaun pengubahan dan pengantian isinya. ${ }^{10}$

b. Metode-Metode Pengajaran Baca Al-Quran

1) Metode lqra'

a) Buku Iqra Privat

Dalam buku Iqra Privat ini terdapat 6 jilid dengan klasifikasi sebagai berikut: ${ }^{11}$

i. Jilid 1, pengenalan huruf hijayyah dari alif hingga ya'.

ii. Jilid 2, pengenalan huruf sambung dan mad dikhususkan pada huruf yang berfathah bertemu alif.

iii. Jilid 3, pengenalan harokat kashroh, dhommah, sukun dan mad pada huruf yang berharokat kashroh bertemu dengan ya' sukun dan huruf yang berharokat dhommah bertemu dengan waw sukun.

iv. Jilid 4, pengenalan huruf yang berharokat tanwin dan cara membaca qalqalah.

v. Jilid 5, pengenalan bacaan alif-lam qamariyah, alif-lam syamsiyah, tanda waqaf, mad far'i, lafdzul jalalah dan idgham.

${ }^{8}$ Rusman, Op Cit, Hal 225-227

${ }^{9}$ Mahmud Yunus, Kamus Arab-Indonesia. Jakarta:Hidakarya Agung. Hal.

335

${ }^{10}$ Abu Bakar Jabir Al-Jazairi, Minhajul Muslim. Cetakan ke-6. Madinah AlMunawwarah: Daarus-Salam. 2010. Hal.22

${ }^{11}$ As'ad Humam. Buku Iqra' Cara Cepat Membaca Al-Quran. Yogyakarta: Balai Litbang LPTQ Nasional 
vi. Jilid 6, pengenalan ilmu tajwid serta cara membaca fawatihus suwar.

b) Buku Iqra Klasikal

Buku iqra klasikal merupakan ringkasan dari buku iqra privat dari jilid 1 sampai 6 . Terdapat 42 bahan ajar dengan 30 pokok bahasan. Iqra kalsikal ini disusun untuk waktu pembelajaran 2 tahun. Berikut pembagiannya: ${ }^{12}$

i. Tahun pertama terdapat 12 pokok bahasan yang terbagi dalam 21 bahan ajar, dengan rincian sebagai berikut; (1) Bahan ajar 1-8 membaca huruf dengan bunyi fathah. (2) Bahan ajar 9-12 membaca huruf sambung. (3) Bahan ajar 13 membaca mad dengan alif mati dan fathah berdiri. (4) Bahan ajar 14 membaca huruf berharokat kasroh dan membaca mad dengan ya' mati. (5) Bahan ajar 15 membaca dan membedakan huruf $\mathrm{Ha}(ه)$ dan membaca mad dengan kasroh berdiri serta membaca Ta' Marbuthoh (o). (6) Bahan ajar 16 membaca dengan harokat dhommah dan membaca mad dengan wau mati. (7) Bahan ajar 17 membaca mad dengan wau mati diikuti alif mati dan membaca mad shilah. (8) Bahan ajar 18 membaca dengan harokat fathatain. (9) Bahan ajar 19 membaca dengan harokat dhommatain dan kasrotain. (10) Bahan ajar 20 membaca dengan fathah yang diikuti ya' mati dan wau mati. (11) Bahan ajar 21 membaca dengan huruf mim mati dan nun mati.

ii. Tahun kedua terdapat 18 pokok bahasanyang terbagi dalam 20 bahan ajar, dengan rincian sebagai berikut; (1) Bahan ajar 22 membaca Qalqalah. (2) Bahan ajar 23 membaca huruf-

${ }^{12}$ As'ad Humam. Buku Iqra' Klasikal Cara Cepat Belajar Membaca AlQuran Sistem Klasikal. Yogyakarta: Balai Litbang LPTQ Nasional. Hal 58-59. 
huruf mati. (3) Bahan ajar 24 membaca hurufhuruf mati dan membaca huruf mati yang hampir sama bunyinya. (4) Bahan ajar 25 membaca alif lam qomariyah dan membaca dengan mewaqofkan harokat fathah, dhommah dan kasroh. (5) Bahan ajar 26 membaca dengan mewaqofkan huruf fathatain dan ta' marbuthoh. (6) Bahan ajar 27 membaca mad lima harokat dan membaca nun bertasydid dan mim bertasydid. (7) Bahan ajar 28 membaca dengan idghom dan membaca alif lam syamsiyah. (8) Bahan ajar 29 membaca huruf bertasydid dan membaca mim mati bertemu huruf ba'. (9) Bahan ajar 30 membaca lafdhul jalalah baik tafhim ataupun tarqiq. (10) Bahan ajar 31 membaca idghom bilaghunnah. (11) Bahan ajar 32 membaca mad enam harokat yang diikuti huruf bertasydid atau mad lazim mutsaqal kalimi. (12) Bahan ajar 33 membaca dengan idghom bigunnah. (13) Bahan ajar 34 membaca dengan iqlab. (14) Bahan ajar 35-37 membaca dengan ikhfa. (15) Bahan ajar 38 membaca dengan mengetahui tanda waqof. (16) Bahan ajar 39 membaca dengan mewaqofkan huruf bertasydid dan membaca dengan mewaqofkan huruf berharokat fathatain. (17) Bahan ajar 40 membaca dengan mewaqofkan huruf hidup yang didahului huruf mati. (18) Bahan ajar 41 membaca dengan mewaqofkan huruf qalqalah yang bertasydid. (19) Bahan ajar 42 membaca fawatihussuwar atau huruf-huruf pada awal surat.

Tahapan pertama pengenalan huruf hijaiyyah dari alif sampai ya' melalui bahan ajar 1-9. Tahapan kedua pengenalan huruf sambung dibahan ajar 9-12. Kemudian pegenalan mad dibahan ajar 13. Tahap terakhir adalah pengetahuan tentang ilmu tajwid dengan 
EVALUASI, 3(2), September 2019, ISSN 2580-3387 (print) |

ISSN 2615-2886 (online)

http://doi.org/10.32478/evaluasi.v3i2.262

prktek bacaan secara langsung dibahan ajar 14-42. Didalam buku iqra' ini juga disertai materi-materi bahan latihan untuk santri yang terdapat dalam iqra privat.

2) Metode Ummi

Metode Ummi adalah sebuah sistem pengajaran AlQuran yang diperuntukkan bagi pra-TK, SD, remaja maupun dewasa. Metode Ummi ini terdiri dari buku Pra-TK, Jilid 1-6, buku Ummi Remaja/Dewasa, Gharib Al-Quran, Tajwid Dasar beserta alat peraga dan metodologi pembelajarannya. ${ }^{13}$

Pencapaian masing-masing jilid tersebut adalah sebagai berikut: ${ }^{14}$

a) Pengenalan huruf tunggal dari alif hingga ya' dan pengenalan harokat fathah.

b) Pengenalan harokat kasroh, dhommah, tanwin, huruf sambung dan angka arab 1-99.

c) Pengenalan mad thabi'i, mad wajib muttashil, mad jaiz munfasil dan pengenalan angka arab dari 100-500.

d) Pengenalan huruf yang disukun dan huruf tasydid.

e) Pengenalan cara membaca waqaf, gunnah, ikhfa', idhgham bigunnah, iqlab dan lafdzul jalalah.

f) Pengenalan qalqalah, idhgham bilagunnah, idzhar, tanda waqaf, nun wiqayah dan fawatihus suwar.

Setelah menyelesaikan jilid 1-6 untuk SD dan jilid 1-3 untuk remaja dan dewasa, diteruskan mempelajari buku tajwid dasar dan gharaibul quran. Dalam buku tajwid dasar akan dikenalkan teori tajwid secara praktis mulai dari hukum

13 Ummi Foundation. Modul Setifikasi Guru Al-Quran Metode Ummi. Surabaya:Ummi Foundation.

${ }^{14}$ Masruri dan Yusuf MS. Belajar Mudah Membaca Al-Quran UMMI 1-6. Surabaya: Ummi Foundation. 2007.

242 
EVALUASI, 3(2), September 2019, ISSN 2580-3387 (print) |

ISSN 2615-2886 (online)

http://doi.org/10.32478/evaluasi.v3i2.262

nun sukun atau tanwin, gunnah, hukum mim sukun, idhgham, lafdzul jalalah, qalqalah, idzhar wajib, hukum ro', hukum lam ta'rif dan mad. ${ }^{15}$ Kemudian dalam buku gharaibul quran akan dikenalkan bacaan-bacaan gharib/ musykilat dalam Al-Quran. ${ }^{16}$

3) Metode Muri-Q

Buku metode Muri-Q atau Murotal Irama Quran merupakan usaha menumbuhkan jiwa kaum muslimin untuk gemar dan cinta Al-Quran dengan sistem pembelajaran dengan mengenalkan kunci-kunci dasar murotal sehingga mudah dipahami dan dipelajari. ${ }^{17}$ Metode ini adalah metode yang menekankan nada murotal pada pembelajarannya. Dalam buku ini terdapat beberapa bagian fokus pembelajaran, diantaranya adalah: ${ }^{18}$

a) Pengenalan huruf hijayyah

b) Pengenalan huruf sambung

c) Pengenalan mad

d) Pengenalan tanda baca selain fathah

e) Pengenalan tanda baca tanwin

f) Pengenalan mim dan nun sukun

g) Pengenalan qalqalah

h) Pengenalan huruf yang disukun selain mim, nun dan qalqalah

i) Pengenalan alif lam qamariyah

j) Pengenalan cara mewaqafkan huruf bertasydid

k) Pengenalan lafdzul jalalah

I) Pengenalan alif lam syamsiyah

m) Pengenalan mad wajib muttashil dan mad jaiz munfashil

${ }^{15}$ Masruri dkk. Belajar Mudah Membaca Al-Quran UMMI Tajwid Dasar. Surabaya: Ummi Foundation. 2007.

16 Masruri dkk. Belajar Mudah Membaca Al-Quran UMMI Gharaibul Quran. Surabaya: Ummi Foundation. 2007.

17 M.Dzikron Al-Hafidz.MURI-Q Murotal Irama Quran.Surakarta:Team Muri-Q.2011. hal. 5

${ }^{18}$ Ibid. Hal. 7-79 
EVALUASI, 3(2), September 2019, ISSN 2580-3387 (print) |

ISSN 2615-2886 (online)

http://doi.org/10.32478/evaluasi.v3i2.262

n) Pengenalan mim tasydid dan nun tasydid

o) Pengenalan idgham bigunnah

p) Pengenalan ikhfa' haqiqi

q) Pengenalan iqlab

r) Pengenalan idgham mimi dan ikhfa' syafawi

s) Penegenalan idzhzr halqi

t) Pengenalan idzhar syafawi dan idgham bilaghunnah

u) Dan latihan membaca potongan-potongan ayat

Pada Muri-Q ini memiliki kunci-kunci dasar atau tingkatan nada. Dasar lagu dalam Muri-Q yang harus dikuasai adalah nada dasar 2 atau nada naik,nada 3 atau nada turun dan untuk nada 1 serta 4 adalah nada variasi.Penggunaan atau penerapannya adalah sebagai berikut:

a) Apabila membaca 1 huruf dibaca $3 x$ dengan nada datardatar-turun.

b) Apabila membaca 2 huruf dibaca $3 x$ dengan nada naikdatar-turun.

c) Apabila membaca 3 huruf dibaca $2 x$ dengan nada naikturun.

d) Apabila membaca 2, 3 dan 4 huruf dibaca $3 x$ dengan nada naik-datar-turun.

e) Apabila membaca 2, 3 dan 4 huruf dibaca $4 x$ dengan nada naik-datar-datar-turun.

f) Dan apabila masih dalam rangkaian ayat, maka memakai kunci dasar:

i. Nada 1: tinggi

ii. Nada 2: Naik

iii. Nada 3: Datar

iv. Nada 4: Turun

\section{Metode Penelitian}

Analisis data yang dilakukan dengan menggunakan data kualitatif yang bersifat deskriptif dengan metode pengumpulan data berupa Fiel Research atau riset lapangan, yang menggunakan hal-hal berikut ini: 
EVALUASI, 3(2), September 2019, ISSN 2580-3387 (print) |

ISSN 2615-2886 (online)

http://doi.org/10.32478/evaluasi.v3i2.262

1. Metode observasi adalah teknik pengamatan dan pecatatan sistematis dari fenomena-fenomena yang dislidiki yang dilakukan untuk menemukan data dan informasi. ${ }^{19}$

2. Metode wawancara atau Interview adalah proses pengumpulan data melalui suatu proses interaksi dan komunikasi antara pewawancara dan responden. ${ }^{20}$ Wawancara ini berbentuk tanya jawab secara tatap muka yang dilaksanakan oleh pewawancara dengan orang yang diwawancarai untuk memperoleh informasi yang dibutuhkan. ${ }^{21}$

3. Metode dokumentasi adalah metode penelitian dengan mengumpulkan dan mencari data mengenai hal-hal yang berkaitan dengan penelitian. ${ }^{22}$ Yaitu pengumpulan data oleh peneliti dengan menelusuri berbagai macam dokumen seperti buku, majalah, koran, notulen rapat, peraturan-peraturan dan sumber informasi lain. ${ }^{23}$

4. Metode triangulasi adalah teknik pengumpulan data yang bersifat menggabungkan dari berbagai teknik pengumpulan data dan sumber data yang telah ada. ${ }^{24}$

Sedangkan tehnik analisis data kualitatif yang kami gunakan adalah teknik analisis data yang disampaikan oleh Miles dan Huberman, ${ }^{25}$ yaitu:

1. Data Reduction atau reduksi data adalah merangkum, memilih halhal yang pokok, memfokuskan pada hal-hal yang penting, dicari tema dan polanya. Dan merupakan bentuk analisis yang menajamkan, menggolongkan, mengarahkan, membuang yang tidak perlu dan mengorganosasi data sehingga kesimpulan akhir dapat diambil.

19 Mahmud, Metode Penelitian Pendidikan.Cetakan X. Bandung: Pustaka Setia, 2011. Hal.168.

${ }^{20}$ Marsi Singarimbun dan Sofian Effendi, Metode Penelitian Survai, Cetakan II, Jakarta: LP3ES, 1991. Hal 192

${ }^{21}$ Sandjaja dan Albertus Heriyanto, Panduan Penalitian, Cetakan I, Jakarta: Prestasi Purtaka Publisher, 2006. Hal.145

22 Suharsimi Arikunto, Prosedur Penelitian Suatu Pendekatan Praktik, Jakarta: Bina Aksara, 1983. Hal 132

${ }^{23}$ Sandjaja dan Albertus Heriyanto, Op Cit., hal. 144

24 Sugiyono, Metode Penelitian Kuantitatif, Kualitatif, dan $R \& D$, Bandung:Alfabeta, 2013. Hal.241

${ }^{25}$ Ibid, hal.246-252 
EVALUASI, 3(2), September 2019, ISSN 2580-3387 (print) |

ISSN 2615-2886 (online)

http://doi.org/10.32478/evaluasi.v3i2.262

2. Data Display atau penyajian data dilakukan dalam bentuk uraian singkat, bagan, hubungan antar kategori dan sejenisnya. Namun, penyajian data ini paling sering dengan menggunakan teks yang bersifat naratif.

3. Conclusion Drawing atau penarikan kesimpulan dan verivikasi adalah hasil analisis yang dapat digunakan untuk mengambil tindakan.

Ketiga proses ini berlangsung terus-menerus selama penelitian berlangsung.

\section{Hasil Penelitian}

Berdasarkan hasil penelitian yang dilakukan penulis di Masjid AlKarimah Pokoh Wonoboyo Wonogiri, penulis mendapatkan hasil sebagai berikut:

1. Perencanaan Penerapan Metode Tsaqifa dengan Metode Pembelajaran Kooperatif pada Pengajaran Baca Al-Quran

Ustadzah Tini merupakan pendiri sekaligus pengajar dalam kegiatan pengentasan buta aksara hijaiyyah dengan Tsaqifa sejak awal kemunculan Tsaqifa di Desa Wonoboyo. Untuk penerapan Tsaqifa pada pengajian ini, Ustadzah melakukan beberapa langkah untuk mendukung tercapainya tujuan mempelajari huruf hijaiyyah ini. Langkah-langkah tersebut antara lain:

a. Pembukaan (10 Menit)

1) Salam

2) Menyakan kabar

3) Doa pembuka; Al-Fatihah, Al-Baqarah 1-7 dan Thahaa 25-27

b. Pemberian materi Tsaqifa klasikal (20 Menit)

c. Pendalaman materi Tsaqifa dimasing-masing kelompok (40 Menit)

d. Penutupan (10 Menit); Tausiyah, doa penutup majelis, salam penutup. ${ }^{26}$

2. Penerapan Metode Tsaqifa dengan Metode Pembelajaran Kooperatif pada Pengajaran Baca Al-Quran

${ }^{26}$ Wawancara dengan pengajar Tsaqifa. 
Proses pelaksanaan dilapangan yang dilaksanakan oleh Ustadzah Tini adalah sebagai berikut:

a. Pembukaan (10 Menit)

Pada pengajian ini dimulai pada pukul 15.45 WIB dengan salam dari Ustadzah dianjutkan menanyakan kabar anggota pengajian dengan mengabsen kehadiran masing-masing anggota. Ketika anggota sudah siap untuk belajar akan dimulai dengan doa pembuka dengan membaca Al-Fatihah, Al-Baqarah 1-7 dan Thahaa 25-27. Waktu yang digunakan kurang lebih 10 menit.

b. Pemberian materi Tsaqifa klasikal (20 Menit)

Pemberian materi Tsaqifa perbab disampaikan secara klasikal oleh Ustadzah. Pada pemberian materi ini berlangsung kurang lebih 10 menit dan dilanjutkan ke pendalaman materi dimasing-masing kelompok.

Dimulai bab I hingga bab VII secara urut. Untuk menyelesaikan 7 bab ini, pengajian ini memerlukan waktu 7 kali pertemuan. Seperti yang Ustadzah sampaikan kepada penulis bahwa dalam satu kali pertemuan hanya satu bab saja yang dipelajari agar semua anggota menguasai, dengan tidak ada pengulangan dibab yang telah dipelajari dipekan-pekan sebelumnya. Hal ini dimaksudkan agar anggota pengajian senantiasa mengulang pelajarannya dirumah.

c. Pendalaman materi Tsaqifa dimasing-masing kelompok (40 Menit)

Pendalaman materi pada setiap bab dilakukan dalam kelompok. Untuk pengelompokan anggota, Ustadzah membagi anggota kedalam beberapa kelompok dengan menempatkan anggota yang sudah pernah belajar baca tulis Al-Quran dan anggota yang belum pernah belajar baca tulis Al-Quran kedalam masing-masing kelompok. Hal ini bertujuan agar anggota yang sudah pernah belajar baca tulis Al-Quran bisa mengajari anggota yang belum pernah belajar baca tulis Al-Quran. 
Sedangkan Ustadzah memantau dari beberapa kelompok tersebut untuk mengetahui anggota-anggota yang masih kesulitan belajar untuk bisa dibimbing secara khusus. Hal ini disampaikan oleh Ustadzah kepada penulis tentang beberapa anggota yang belum bisa mengejar ketertinggalan dalam belajar mereka. Ustadzah memberikan alternatif bagi anggota yang belum bisa untuk bisa belajar diluar jam pengajian. ${ }^{27}$

Salah satunya adalah ibu Sukini yang usianya saat ini 65 tahun. Pada awalnya beliau sulit mengikuti cara belajar menggunakan Tsaqifa yang singkat. Kemudian beliau diajari oleh Ustadzah diluar jam pengajian dan alhamdulillah saat ini beliau sudah bisa mengkuti tadarus bersama anggota-anggota yang lain.

Seperti yang beliau tuturkan kepada penulis bahwa beliau merasa kesulitan untuk mengikuti belajar Tsaqifa ini terutama dalam mengingat huruf-huruf hijaiyyah yang hampir sama bentuknya. Tetapi beliau tetap bersyukur karena saat ini sudah bisa membaca Al-Quran walaupun dengan terbata-bata. ${ }^{28}$

d. Penutupan (10 Menit)

Tausiyah dan doa penutup, diisi oleh Ustadzah berkaitan tentang niat dan keutamaan-keutamaan orang-orang yang belajar Al-Quran. Hal ini bertujuan untuk memurnikan niat masing-masing anggota dalam belajar membaca Al-Quran. Diakhir pertemuan ditutup dengan doa penutup majelis bersama-sama dilanjutkan berjabat tangan sebelum keluar masjid. Kegiatan ini berakhir pada pukul 17.05 WIB bahkan terkadang hingga menjelang maghrib. ${ }^{29}$

Setelah selesai pengajaran Tsaqifa, Ustadzah tidak sertamerta menghentikan pengajian ini, tetapi tetap membersamai para anggota kelompok pengajian ini hingga saat ini. Terhitung sejak mulai

\footnotetext{
${ }^{27}$ Wawancara dengan pengajar Tsaqifa

${ }^{28}$ Wawancara dengan anggota pengajian

${ }^{29}$ Observasi dan Wawancara dengan pengajar Tsaqifa
} 
EVALUASI, 3(2), September 2019, ISSN 2580-3387 (print) |

ISSN 2615-2886 (online)

http://doi.org/10.32478/evaluasi.v3i2.262

belajar Tsaqifa hingga Al-Quran saat ini kurang lebih sudah 3 tahun lamanya.

3. Hasil Penerapan Metode Tsaqifa dengan Metode Pembelajaran Kooperatif pada Pengajaran Baca Al-Quran

Dari observasi yang penulis lakukan selama beberapa waktu di pengajian tersebut, bisa dilihat hasil pengajaran dan pembinaan yang dilakukan oleh Ustadzah dalam belajar Tsaqifa.

Saat ini terdapat 17 anggota aktif dalam pengajian ini. Kegiatan pengajian ini difokuskan pada tilawah Al-Quran setiap pekannya. Adapun kegiatan lain sebatas sebagai tambahan saja seperti penyampaian hadits-hadits Nabi, tausiyah dan terjemah AlQuran menjelang akhir pertemuan.

Dalam tilawah pekanan tidak hanya meneruskan surat yang dibaca pekan sebelumnya saja tetapi Ustadzah memasukkan suratsurat penting dalam Al-Quran untuk doa pembuka mengawali tilawah pada hari-hari pengajian itu berlangsung.

Rincian acara pekanan sebagai tindak lanjut pengajaran Tsaqifa adalah sebagai berikut; yang pertama, pembukaan (10 Menit), dilakukan secara klasikal dengan membaca surat dan ayat dibawah ini:
a. Qs. Al-Fathihah
b. Qs. Al-Baqarah 1-7
c. Qs. Thaha 25-27
d. Qs. Al-Baqarah 284-286

Yang kedua, dilanjutkan tilawah pekan sebelumnya (30 Menit), dengan rincian:

a. Membaca secara bersama-sama 1 halaman

b. Membaca 1-2 ayat bergilir, tujuannya untuk mengetahui bacaan Al-Quran masing-masing anggota biasanya 1-2 putaran.

c. Membaca bersama-sama lagi hingga akhir halaman diakhir pertemuan. 
Yang ketiga, penutupan; pada 10 menit terakhir disampaikan terjemah ayat Al-Quran yang sudah dimulai dari Qs. Al-Baqarah dilanjutkan tausiyah atau penyampaian hadits. ${ }^{30}$

Untuk sekali pertemuan, pengajian ini mampu menyelesaikan 7 hingga 10 halaman Al-Quran.

Dalam kegiatan pekanan ini, Ustadzah juga melatih ketrampilan masing-masing anggota untuk bisa membuka atau mengawali sebuah acara pengajian. Selain acara pekanan ini Ustadzah juga mengadakan agenda rutin bersama seluruh binaan majelis taklim di desa Wonoboyo. Dan salah satunya untuk menambah semangat belajar membaca Al-Quran binaan atau jamaah masjid Al-Karimah ini, Ustadzah mengadakan acara Khotmil Quran jika pengajian tersebut telah mengkhatamkan Al-Quran. Kegiatan ini sudah dilaksanakan pada Ramadhan tahun lalu ketika pengajian ini mengkhatamkan Al-Qurannya.

\section{E. Kesimpulan dan Saran}

\section{Kesimpulan}

Pada prakteknya, Ustadzah pengampu Tsaqifa hanya menggunakan waktu 60 menit setiap pertemuannya. Beliau tidak menggunakan waktu hingga 90 menit sehingga hal ini membuat waktu menyelesaikan Tsaqifa menjadi 7 pertemuan. Walaupun berbeda dengan yang ditetapkan oleh Tsaqifa yaitu 5 kali pertemuan dengan masing-masing pertemuan 1,5 jam tetapi pada dasarnya waktu yang dibutuhkan sama yaitu kurang lebih 7,5 jam. Bahkan dengan 7 kali pertemuan dengan masing-masing 1 jam waktu yang digunakan justru lebih singkat yaitu 7 jam saja.

Pengajaran Tsaqifa yang fleksibel ini diterapkan juga oleh Ustadzah dengan baik, privat ataupun klasikal. Privat bagi anggota yang belum bisa mengikuti belajar klasikal berkelompok dan klasikal berkelompok untuk anggota-anggota yang sudah bisa belajar Tsaqifa secara bersama-sama.

\footnotetext{
${ }^{30}$ Observasi
} 
EVALUASI, 3(2), September 2019, ISSN 2580-3387 (print) |

ISSN 2615-2886 (online)

http://doi.org/10.32478/evaluasi.v3i2.262

Penerapan pembelajaran Tsaqifa dengan pembelajaran kooperatif ini telah mampu menuntaskan warga Dusun Pokoh Desa Wonogiri ini dari buta aksara Hijaiyyah.

\section{Saran}

Dalam belajar Al-Quran ada saat-saat sulit yang kadang membuat orang-orang putus asa dalam belajar. Kesulitan dalam mengingatingat huruf, kesulitan mengikuti tilawah dan kesulitan-kesulitan lain. Untuk itu penulis mengharapkan agar ibu-ibu anggota pengajian tetap sabar dalam belajar dan istiqamah mengikuti jalannya pengajian setiap pekannya.

Sebagai pengajar Al-Quran sebaiknya juga menguasai kidahkaidah tajwid dan ilmu tahsin walaupun keduanya belum diajarkan sejak awal belajar Al-Quran. Yang terpenting adalah makhorijul huruf harus tuntas dalam step pertama.

\section{F. DAFTAR PUSTAKA}

Abu Bakar Jabir Al-Jazairi. 2010. Minhajul Muslim. Cetakan ke-6. Madinah Al-Munawwarah: Daarus-Salam.

As'ad Humam. Buku Iqra' Klasikal Cara Cepat Belajar Membaca AlQuran Sistem Klasikal. Yogyakarta: Balai Litbang LPTQ Nasional.

As'ad Humam. Buku Iqra' Cara Cepat Membaca Al-Quran. Yogyakarta:Balai Litbang LPTQ Nasional

Mahmud Yunus. Kamus Arab-Indonesia. Jakarta:Hidakarya Agung.

Mahmud. 2011. Metode Penelitian Pendidikan.Cetakan X. Bandung: Pustaka Setia.

Marsi Singarimbun dan Sofian Effendi. 1991. Metode Penelitian Survai,Cetakan II, Jakarta: LP3ES.

Masruri dan Yusuf MS. 2007. Belajar Mudah Membaca Al-Quran UMMI 1-6. Surabaya:Ummi Foundation. 
EVALUASI, 3(2), September 2019, ISSN 2580-3387 (print) |

ISSN 2615-2886 (online)

http://doi.org/10.32478/evaluasi.v3i2.262

Masruri dkk. 2007. Belajar Mudah Membaca Al-Quran UMMI Tajwid Dasar. Surabaya:Ummi Foundation.

Masruri dkk. 2007. Belajar Mudah Membaca Al-Quran UMMI Gharaibul Quran. Surabaya:Ummi Foundation.

M.Dzikron Al-Hafidz. 2011. MURI-Q Murotal Irama Quran.Surakarta:Team Muri-Q.

Rusman. 2012. Model-Model Pembelajaran Mengembangkan Profesionalisme Guru. Cetakan ke-5.Depok:Raja Grafindo Persada.

Sandjaja dan Albertus Heriyanto. 2006. Panduan Penalitian. Cetakan I. Jakarta: Prestasi Purtaka Publisher.

Sugiyono. 2013. Metode Penelitian Kuantitatif, Kualitatif, dan R\&., Bandung:Alfabeta.

Suharsimi Arikunto.1983.Prosedur Penelitian Suatu Pendekatan Praktik. Jakarta: Bina Aksara.

Trianto.2009. Mendesain Model Pembelajaran Inovatif-Progresif. Cetakan ke-1. Jakarta: Kencana.

Umar Taqwim. Tsaqifa, Cara Cepat dan Mudah Belajar Membaca AlQuran.Cetakan ke-30. Magelang: Adz-Dzikr

Umar Taqwim. 7 1/2 Jam Bisa Membaca Al-Quran.Cetakan ke-VII Sukoharjo: Nur Cahaya IImu.

Ummi Foundation. Modul Setifikasi Guru Al-Quran Metode Ummi. Surabaya:Ummi Foundation. 